\title{
Effect of the Surface Roughness on the Shear Strength of Granular Materials in Ring Shear Tests
}

\author{
Sueng-Won Jeong ${ }^{1}$ and Sung-Sik Park ${ }^{2, *}$ \\ 1 Korea Institute of Geoscience and Mineral Resources, Daejeon 34132, Korea \\ 2 Department of Civil Engineering, Kyungpook National University, 80 Daehakro, Bukgu, Daegu 41566, Korea \\ * Correspondence: sungpark@knu.ac.kr
}

Received: 27 June 2019; Accepted: 24 July 2019; Published: 25 July 2019

\begin{abstract}
Surface roughness plays an important role in estimating the shear strength of granular materials. A series of ring shear tests with different surface roughnesses (i.e., smooth and rough surfaces) were performed. A large-sized ring shear device, which is applicable for fine- and coarse-grained sediments, was developed to examine the shear strength of large particle sizes (i.e., commercial gravels with a mean grain size of $6 \mathrm{~mm}$ ). In terms of surface roughness, the drainageand shear-velocity-dependent shear strengths of the granular materials were examined. In this study, different shear velocities of $0.1,0.5$, and $1 \mathrm{~mm} / \mathrm{s}$ were applied under drained and undrained conditions. The test results clearly show that shear stress is affected by drainage, shear velocity, and surface roughness. In particular, a typical strain-hardening behavior is exhibited regardless of the drainage and shear velocity condition. The measured shear strength obtained from both drained and undrained conditions increased with increasing shear velocity. All tests showed a large fragmentation using rough surfaces compared to the smooth surfaces of the device. The grain crushing was significant during shearing, even when normal stress was not applied. For a given shear velocity, surface roughness is an important feature in determining the shear strength of granular materials.
\end{abstract}

Keywords: surface roughness; granular material; gravel; ring shear test; grain crushing

\section{Introduction}

The shear strength of granular materials is a very important parameter in engineering practice when examining the frictional and viscous characteristics of geomaterials [1,2]. Granular materials have complicated shear deformation characteristics involving solid- and liquid-like behaviors $[3,4]$. A previous study found that granular materials have much more complex elastoplastic and viscous behaviors than materials with finer particles [5]. For this reason, surface roughness has often been taken into account in examining soil-structure interactions in geotechnical engineering practices for piles, foundations, retaining walls, tunnels, embankment, and earth reinforcement [6-10], because the soil-structure interaction is significantly influenced by the material's properties, shape, roughness, and loading conditions (i.e., monotonic and cyclic loading). Numerous studies have focused on the frictional and viscous behaviors of loose and dense sands as representative granular matter $[6,11]$. According to $\mathrm{Hu}$ and $\mathrm{Pu}$ [8], for a sandy size particle $(0.075-2 \mathrm{~mm})$, elastic perfect-plastic behavior is dominant for a smooth interface, while strain localization is dominant for a rough interface.

The importance of surface roughness in various grain sizes has also been evaluated and presented by numerous researchers, because inter-particle friction can be affected by the Young's modulus, particle shape, and surface roughness of the materials [11-13]. The reason for this is that natural materials have a wide spectrum of surface features in nature; it has generally been observed that inter-particle friction increases with surface roughness. According to Shahrour and Rezaie [11], the friction angle depends on both sand density and interface roughness. In order to investigate the effect of roughness 
on the frictional behavior of particle-particle and soil-structure interfaces, different types of tests have been used under monotonic and cyclic loading: The simple shear test [14,15], the direct shear test $[8,9]$, and the ring shear test $[16,17]$.

The effect of surface roughness on the mechanical behavior of granular materials is also crucial for natural disaster prediction and prevention, such as landslides and debris flows. In landslide areas, the mechanical properties that may lead to rock avalanches with rapid, massive, and dynamic movements of fragmented rocks are evaluated by the surface roughness determined by in situ and laboratory tests $[9,18]$. In geology, joints and weathering are related to fragmentation [19]. The shear strength, permeability, and compressibility of granular materials are also greatly affected by the fragmentation phenomenon when they are subjected to changes in stress. An empirical method to estimate the travel distance of fragmented rocks in the Wenchuan earthquake area was presented by Zhan et al. [1]. High mobile mass movements can be caused by the soft base effect [20], which is related to the increase of fine-grained sediment during a landslide motion. In general, the surface roughness of granular materials may result in particle breakage, also called grain crushing. In the shear stress (or force) and strain relationship, three stages of particle breakage under compression can be identified: (i) Local rearrangements and sliding, (ii) fragmentation by abrasion, and (iii) fragmentation by fracture [21]; it is assumed that grain fragmentation can be characterized by the progressive propagation of a transversal crack (including compression, abrasion, and fracture) inside the grain. In general, the breakage potential of a soil particle increases with its size [22]. Using a large-sized ring shear apparatus, particle breakage can be measured by the grain size distribution curve before and after shearing [23,24]. However, the mechanical behavior due to particle breakage in different drained and shear velocity conditions is not fully understood. In assessing landslide mobility, the mechanical deformation from failure to post-failure may affect the shear zone formation, which depends on the potential for grain crushing to occur. Thus, in a traditional laboratory test condition using a smooth surface for a given loading, the underestimation of shear stress appears to be inevitable.

The objective of this study was to examine the effect of surface roughness on the shear strength of gravels, as a granular matter, in the ring shear test. First, the characteristics of shear stress are examined as a function of the drainage and shear velocity. Second, the surface roughness effect under drained and undrained conditions is compared for different shear velocities. Third, the determined shear strength and shear velocity relationships are discussed. Finally, the grain crushing effect is highlighted using a grain size distribution analysis of gravels before and after the tests. However, the roughness of the grain itself, cyclic behavior, and the strain rate effect based on the grain size were considered to be beyond the scope of this study.

\section{Materials and Methods}

\subsection{Materials}

Commercial aquarium gravel with different grain sizes of 5-10 mm was used, because it may result in higher fragmentation than the fines. The mean rounded shape value was approximately 6 $\mathrm{mm}$ (Figure 1). The dry densities were 1.839 and $1.725 \mathrm{~g} / \mathrm{cm}^{3}$. To represent an unbroken loose state of gravel, a total of $4500 \mathrm{~g}$ contained in a ring shear box with a hollow cylinder volume of $2580 \mathrm{~cm}^{3}$ was considered in all tests. Grain size analyses were conducted for unbroken and broken gravel particles before and after the tests, respectively. 

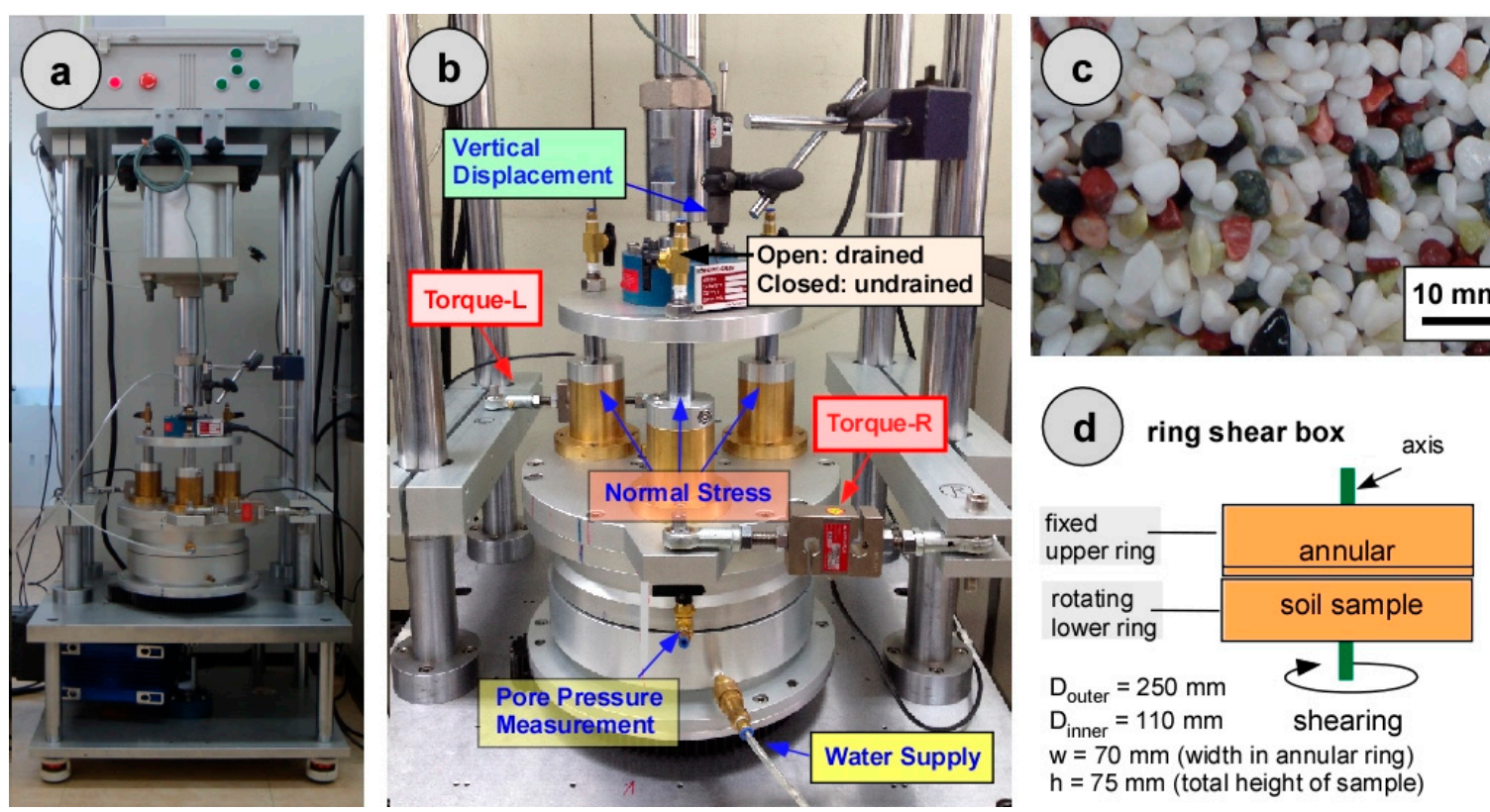

Figure 1. Ring shear apparatus and material: (a) Ring shear apparatus; (b) ring shear box; (c) gravel; and (d) schematic view of ring shearing.

\subsection{Methods}

\subsubsection{Ring Shear Test}

A ring shear apparatus is commonly used to examine the residual shear strength of soils based on a shear stress-shear strain relationship. It is a well-known special instrument with an artificial slip surface that allows for measurements of the shear stress when forces act on a sample [25-27]. One of the main advantages of the ring shear test is the unlimited shear deformation developed in a soil sample. There is a constant contact area during the test, so extra stress concentration with large shear deformation does not occur [8]. To investigate the undrained shear strength of soils, a large-sized ring shear apparatus was developed by various researchers [17,25-29]. This ring shear device is easy to assemble and has simple drainage and shear velocity control systems (Figure 1). The device incorporates one of the largest ring shear boxes, with a maximum outer diameter of $250 \mathrm{~mm}$. It is applicable for both fine- and coarse-grained sediments. The samples were contained in the ring shear box, which is also called the ring shear cell [30]. Vertical loading can be applied to the samples through three piston chambers (Figure 1a,b). However, normal stress-dependent frictional strength and shear zone formation were beyond the scope of this study.

After mounting, the drained or undrained condition is selected using the open/close valve in the upper plate. The shear velocity can be varied from 0.01 to $100 \mathrm{~mm} / \mathrm{s}$. In this study, three shear velocities were selected: $0.1,0.5$, and $1 \mathrm{~mm} / \mathrm{s}$, with a particular emphasis placed on surface roughness. These velocities were selected because the grain crushing of gravel is much higher (excessive) when the shear velocity is higher than $1 \mathrm{~mm} / \mathrm{s}$ in ring shear tests [30]. However, the effect of surface roughness on the shear stress in the shear zone is not clear, because the inside of the ring shear box cannot be observed during the test. Normal stress was not applied during the tests regardless of the drainage condition; that is, the upper ring plate just contacts the upper part of the gravel material being tested without applying any load because the frictional behavior is strongly influenced by applied normal stress $[8,11]$, which was not the focus of this study. The grain size and surface roughness also have significant influence on the shear resistance [14]. To minimize the normal stress effect on the granular materials, a constant normal stress is applied during a test (i.e., $0 \mathrm{kPa}$ ). However, the gravel may resist the dilative force during shearing when the normal stress is applied to maintain a zero vertical loading value. Thus, the materials tested are continuously subjected a contractive force, which could 
be negligible within the relatively low shear velocities imposed (e.g., $0.1-1 \mathrm{~mm} / \mathrm{s}$ ). During the tests, the shear stresses (i.e., the torques) were measured by two arms on the sides of the ring shear box. The variations in vertical displacement and normal stress were also measured. The testing procedures were identical to those detailed by Sassa et al. $[25,26]$.

\subsubsection{Surface Roughness in the Ring Shear Box}

The annular-like shape of the ring shear box has an inner diameter of $110 \mathrm{~mm}$, an outer diameter of $250 \mathrm{~mm}$, and a height of $75 \mathrm{~mm}$ (Figure 2). The width between the inner and outer sides of the annular-shaped shear box is $70 \mathrm{~mm}$. The height of the materials in the ring shear box can be varied from 70 to $80 \mathrm{~mm}$, but a fixed height of $75 \mathrm{~mm}$ was applied in the tests. In this context, a wide range of large particle sizes (e.g., $0.075-10 \mathrm{~mm}$ ) can be accommodated within the box. To minimize the slip effect, surface roughness is required for many types of instruments when investigating an engineering problem. In some tests, a thick sand cover with a rough surface texture was used for clayey to sandy soils. In this study, two types of ring shear boxes with smooth (classic) and rough (serrated) surfaces were made and placed inside the inner and outer sidewalls of the ring shear box to examine the frictional and fragmentation effects during shearing. No roughness was considered for the classic ring shear box except at the top and bottom. In the upper and lower plates, a combination of porous stone and 12 saw-like surfaces was used. The rough surfaces in the second ring shear box were located inside the inner and outer sides of the hollow cylinder box (Figure 2b-d). The dimensions of the rough surfaces were fixed. The thickness, width, and height were $5 \mathrm{~mm}, 3 \mathrm{~mm}$, and $22 \mathrm{~mm}$, respectively, for the lower ring, and $5 \mathrm{~mm}, 3 \mathrm{~mm}$, and $26 \mathrm{~mm}$, respectively, for the upper ring. In total, there were 32 inner rough surfaces and 72 outer rough surfaces. Because of the dimensions of the rough surfaces, large particle sizes were well sheared at the inner and outer perimeters of the shear box. In particular, the roughness was considered capable of directly affecting the gravelly soil tested (mean grain size of $6 \mathrm{~mm}$ ).

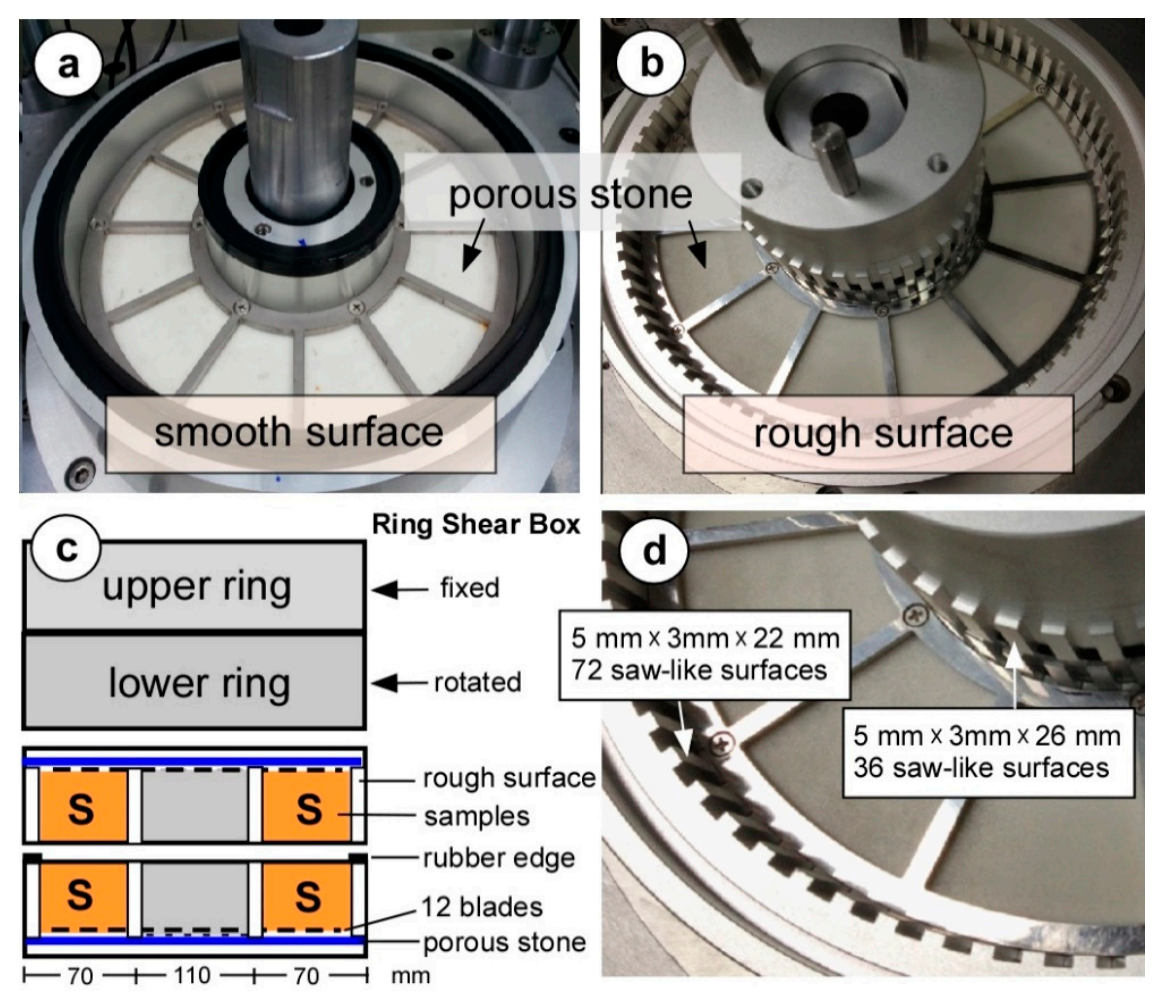

Figure 2. Ring shear box: (a) Smooth surface; (b) rough surfaces; (c) schematic view; and (d) inside view with inner and outer rough surfaces. 


\section{Results}

The test results indicated the shear characteristics of gravels, the minimization of the wall slip due to the rough surfaces in the inner and outer hollow cylinder box, the measured shear stress as a function of the shear velocity, and the grain crushing effect with respect to surface roughness at different drainage conditions and shear velocities.

\subsection{Shear Characteristics of Gravel in the Ring Shear Tests}

Ring shear tests were initially performed using a classic smooth surface for the aquarium gravel with a normal stress of $0 \mathrm{kPa}$ and a velocity of $0.5 \mathrm{~mm} / \mathrm{s}$. The mechanical properties of materials can often be described by their shear stress and shear strain (or displacement) relationship in response to the applied load. Figure 3 shows that in the shear stress-shear time relationship, the particles exhibited a typical strain-hardening behavior, regardless of the drainage condition, which implies that shear stress increases with increasing shear strain. This may be considered a shear resistance (i.e., yield strength) occurring at the beginning of plastic behavior based on the rheology. There was no contractive or dilative behavior apparent during shearing. Because the normal stress remained constant during shearing, very little decrease in the height of the sample was observed (the variation was less than $0.1 \mathrm{~mm}$ ). According to Terzaghi et al. [31], typical dense sand and over-consolidated clays are dilative, while loose sands and normally consolidated clays are contractive. There was little effect based on the drainage condition. At the end of the test, as shown in Figure 3, the maximum shear strength was approximately $20 \mathrm{kPa}$. The minor variation in normal stresses with both drained and undrained conditions was caused by particle rearrangement, interlocking, and fragmentation along the artificial sliding plane during the ring shear test (Figure 3c,f). In the drained condition, after $1200 \mathrm{~s}$, there was a slight decrease in shear stress, which may occur because the strain localization due to grain crushing was more significant in the drained condition; the large particles in the drained condition could freely move from the upper part to the middle part (artificial sliding plane) within the ring shear box. Similar results were reported by Sassa et al. [26]. The pore water pressure is also an important factor in determining the shear strength in the undrained condition, but in this study, this value was not a major factor because it strongly depends on the drainage and shear velocity. Thus, the measurement of pore water pressure was not considered.
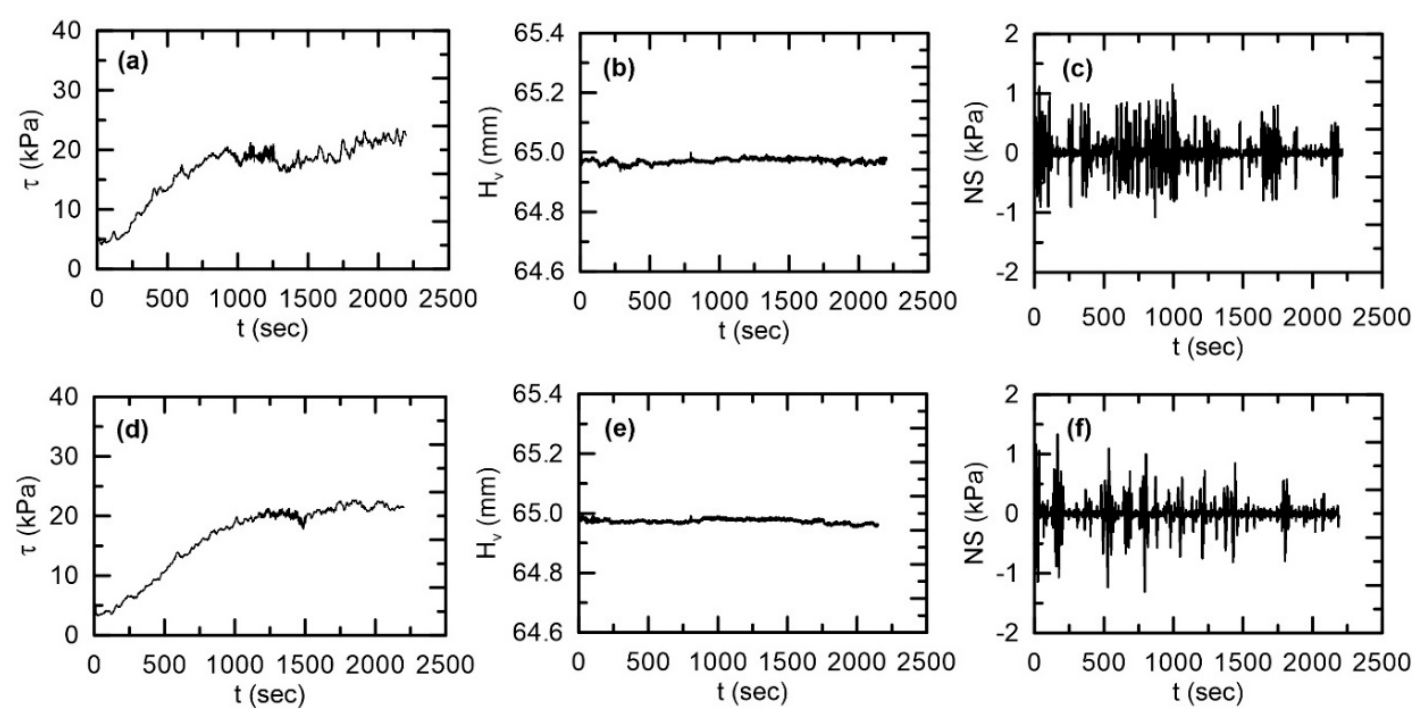

Figure 3. Shear characteristics of gravels using smooth surface test box: (a-c) Drained and (d-f) undrained conditions at $0.5 \mathrm{~mm} / \mathrm{s}$. $\tau=$ Shear stress $(\mathrm{kPa}) ; \mathrm{H}_{\mathrm{v}}=$ Height of soil sample $(\mathrm{mm})$; NS $=$ Normal stress $(\mathrm{kPa})$. 


\subsection{Effect of the Surface Roughness on the Shear Stress}

Figure 4 presents a comparison of the shear strength obtained from the smooth and rough surfaces with respect to the drainage condition drained or undrained) and shear velocity $(0.1,0.5$, and $1 \mathrm{~mm} / \mathrm{s})$. The shear stress-time relationship was considered because the total displacements of the materials tested were not exactly the same for all test conditions, as they may have been different for a given shear velocity. As previously described, the tests were performed over a limited range of shear velocities because rapid shearing may have resulted in an unnecessary reduction in the shear strength of granular materials for higher velocities [32]. From the test results, the shear stress and shear deformation characteristics were very similar for both drainage conditions. The effect of surface roughness on shear stress is crucial when considering a relatively high shear velocity (i.e., $>0.1 \mathrm{~mm} / \mathrm{s}$ ). At $0.1 \mathrm{~mm} / \mathrm{s}$, the shear stress measured from the rough surfaces was slightly larger than from the smooth surfaces; however, at the end of the test, both values were similar at their closest point $(20 \mathrm{kPa}$ for the drained condition and $17 \mathrm{kPa}$ for the undrained condition). At $0.5 \mathrm{~mm} / \mathrm{s}$, the difference in surface roughness was significant (Figure $4 \mathrm{~b}, \mathrm{e}$ ). Compared to the results at $0.1 \mathrm{~mm} / \mathrm{s}$, the shear stress measured from the smooth surface only slightly increased (21-22 kPa), but the shear stress measured from the rough surface greatly increased (33-34 kPa). At the final stage of shearing (at $2200 \mathrm{~s}$ ), the stress difference between smooth and rough surfaces was almost constant $(12 \mathrm{kPa})$. For the shear velocity of $1 \mathrm{~mm} / \mathrm{s}$ (Figure $4 \mathrm{c}, \mathrm{f})$, there was little difference in the stress-time relationships. The difference was small until the shearing time reached approximately $500 \mathrm{~s}$; when shearing was continuously applied, dilatancy was prominent in the rough surfaces. In the drained condition, a larger difference in shear stress was observed when a larger shear velocity was applied, but the difference was small in the undrained condition. These results may be attributed to the presence of shear localization and water in the shear zone.
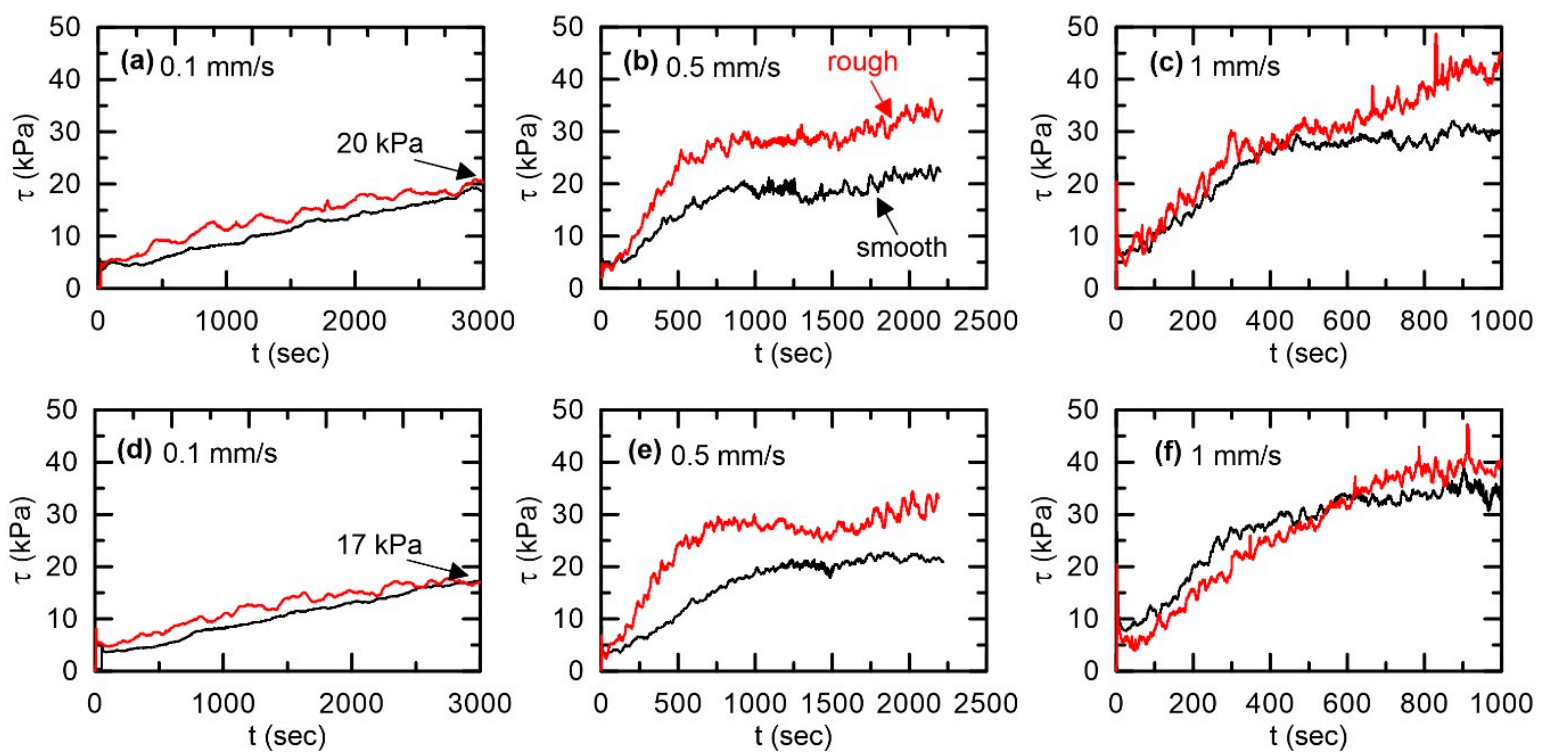

Figure 4. Comparison between smooth and rough surfaces for different shear velocities of $0.1,0.5$, and $1 \mathrm{~mm} / \mathrm{s}$ : $(\mathbf{a}-\mathbf{c})$ Drained and $(\mathbf{d}-\mathbf{f})$ undrained conditions. $(\mathbf{a}, \mathbf{d}): 0.1 \mathrm{~mm} / \mathrm{s} ;(\mathbf{b}, \mathbf{e}): 0.5 \mathrm{~mm} / \mathrm{s}$; and $(\mathbf{c}, \mathbf{f}): 1 \mathrm{~mm} / \mathrm{s}$.

There was no direct observation possible for the soil-structure interaction in ring shear tests using the developed apparatus. However, from the test results, it may be deduced that, in terms of the grain fragmentation, local rearrangement and sliding features were dominant for the shear velocity of $0.1 \mathrm{~mm} / \mathrm{s}$, while local abrasion and global fracture inside the grain were dominant for shear velocities of 0.5 and $1 \mathrm{~mm} / \mathrm{s}$. In brief, from the test results, the surface roughness was of significance, and this proves that the wall slip phenomenon was minimized. However, it is not easy to estimate the fragmentation effect based on shear velocity. 


\subsection{Peak Shear Strength as a Function of Shear Velocity}

From the shear stress and shear displacement relationships, the peak and residual shear strengths could be determined. The maximum and minimum shear strengths were clearly determined from the strain-softening behaviors of materials such as dense sands or over-consolidated clays. According to Toyota et al. [33], there appears to be no shear rate effect for low and high plasticity clays when relatively low shear rates ranging from $10^{-6}$ to $10^{-3} \mathrm{~mm} / \mathrm{s}$ are imposed on the slip surface. In this study, the strain-hardening behavior was dominant for a given drainage and shear velocity; thus, only the peak shear strength (i.e., the final shear stress) could be determined. For convenience, the value at the end of each test was selected. In this context, the ultimate shear strength and residual shear strength could not be determined. For a dense sandy soil-steel interface, Saberi et al. [6] demonstrated that as the roughness increases, the shear strength and friction at the peak increase, but those at the residual state essentially remain unchanged. The latter may be characterized by the thickness of the crushed grain band and the fine content in a shear zone. For gravel, the shear zone thickness can be affected by a relatively high shear speed (e.g., $300 \mathrm{~cm} / \mathrm{s}$, as tested by Sassa et al. [26]) and cyclic motion with surface roughness [10]. Zhang and Zhang [10] demonstrated that a large shear deformation can result in a remarkable thickness of the crushing band near the soil-structure interface for gravelly soils with a mean grain size of $7 \mathrm{~mm}$. In our study, this thickness of the crushing band increased up to a maximum of $24 \mathrm{~mm}$ depending on the shear applied, but it reached a stable state if a large amount of shear deformation occurs.

In general, the shear resistance increases with increasing shear velocity [34,35]. Figure 5 shows the dependence of the peak shear strength on the shear velocity. Regardless of the drainage condition, the values were similar at the same roughness. At the lowest shear velocity, i.e., $0.1 \mathrm{~mm} / \mathrm{s}$, the difference varied from $0.3 \mathrm{kPa}$ to $1.5 \mathrm{kPa}$. However, at the medium shear velocity, i.e., $0.5 \mathrm{~mm} / \mathrm{s}$, the difference varied from $11.7 \mathrm{kPa}$ to $14.6 \mathrm{kPa}$. Compared to the lowest shear velocity, the change in shear resistance increased 10-fold. At the highest shear velocity, i.e., $1 \mathrm{~mm} / \mathrm{s}$, the difference varied from $5.2 \mathrm{kPa}$ to $14.7 \mathrm{kPa}$. The difference in average values of shear strength $(\Delta \mathrm{v})$ obtained from smooth and rough surfaces for each shear velocity were 1,12 , and $10 \mathrm{~mm} / \mathrm{s}$, for $0.1,0.5$, and $1 \mathrm{~mm} / \mathrm{s}$, respectively. The largest difference was found at the shear velocity of $0.5 \mathrm{~mm} / \mathrm{s}$, meaning that this shear velocity may induce an abrasion and fracture-dominant process not present in the $0.1 \mathrm{~mm} / \mathrm{s}$ shear condition. Interestingly, in the drained condition, the shear strength at $1 \mathrm{~mm} / \mathrm{s}$ was almost identical to that at $0.5 \mathrm{~mm} / \mathrm{s}$. However, in the undrained condition, the difference may have decreased by as much as $5 \mathrm{kPa}$. Hence, in the undrained condition, the water in the shear zone played an important role in shearing when measuring the torque in the ring shear test.

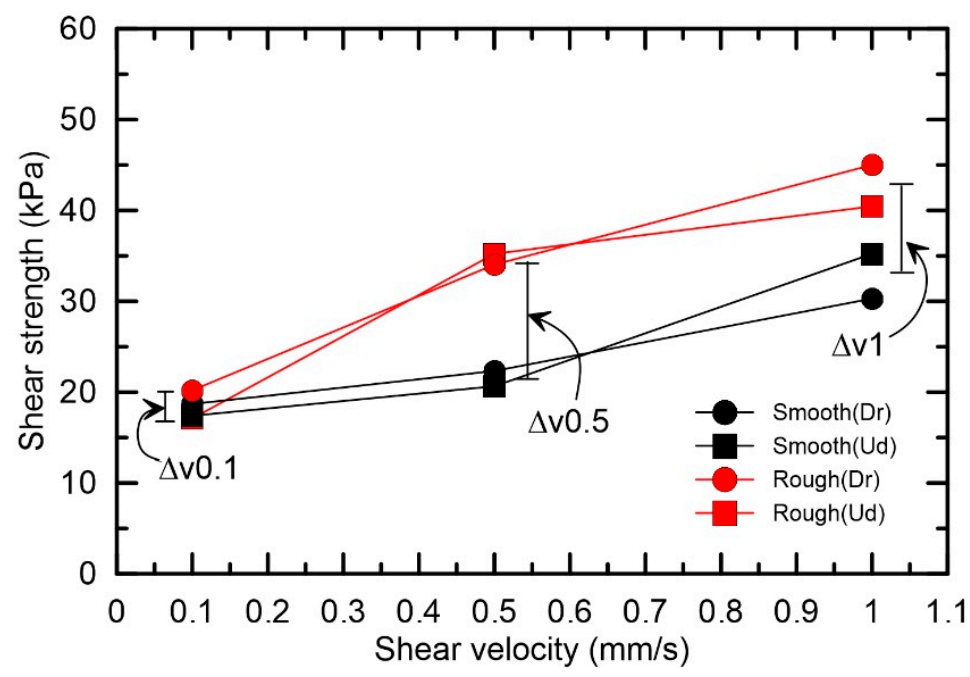

Figure 5. Peak shear strength as a function of the shear velocity. 


\subsection{Grain Crushing Effect with Surface Roughness in the Ring Shear Test}

Particle breakage has a significant effect on soil behavior [22,36]. According to Hardin [22], grain crushing is affected by many factors, e.g., particle shape, state of effective stress, void ratio, particle hardness, and presence of water. A relative breakage potential can be determined using a grain distribution analysis, but this was not considered in this paper. In addition, particle compaction in the ring shear test may result in potential grain crushing and strain localization [30,37]. A grain size analysis was performed for the aquarium gravel using eight sieves before and after the tests. Figure 6 presents the grain size distribution curves with respect to surface roughness depending on the drainage condition and shear velocities of $0.1,0.5$, and $1 \mathrm{~mm} / \mathrm{s}$. As shown in Figure 6, under identical drainage conditions (Figure 6a-f) the grain crushing gradually increased with increasing shear velocity. In each curve, the area created before and after the test could be considered as a fragmentation effect through the artificial sliding plane. From the mechanical viewpoint, the roughness may cause increased friction in both drainage conditions. All tests showed large fragmentation using the rough surfaces compared to the smooth surface, although there was little difference between drained and undrained conditions. For clayey and sandy soils, it may have been easier to locate the shear surface in the test. However, it was much more difficult to visually compare the differences in shear zones obtained from drained and undrained conditions for granular materials because of the invisible slip surface in the ring shear test without using a transparent ring shear box [26]. For the gravel tested, the thickness of the shear zone $\left(h_{s}\right)$ was estimated as 3-6 mm, based on the concept of relative roughness, assuming that $h_{s}=(5$ to 10$) \cdot D_{50}$ [14]. In landslides, a great volume of fine-grained sediments from the entrainment process can affect landslide transformation. For example, Zhang et al. [20] reported that "the fine soil layer carried the slidebody moving fast on the ground and decreased the integrity of the slidebody." Excess pore water pressure and the soft base effect may combine to create a possible mechanism for the transformation from slide to debris flow in landslides.
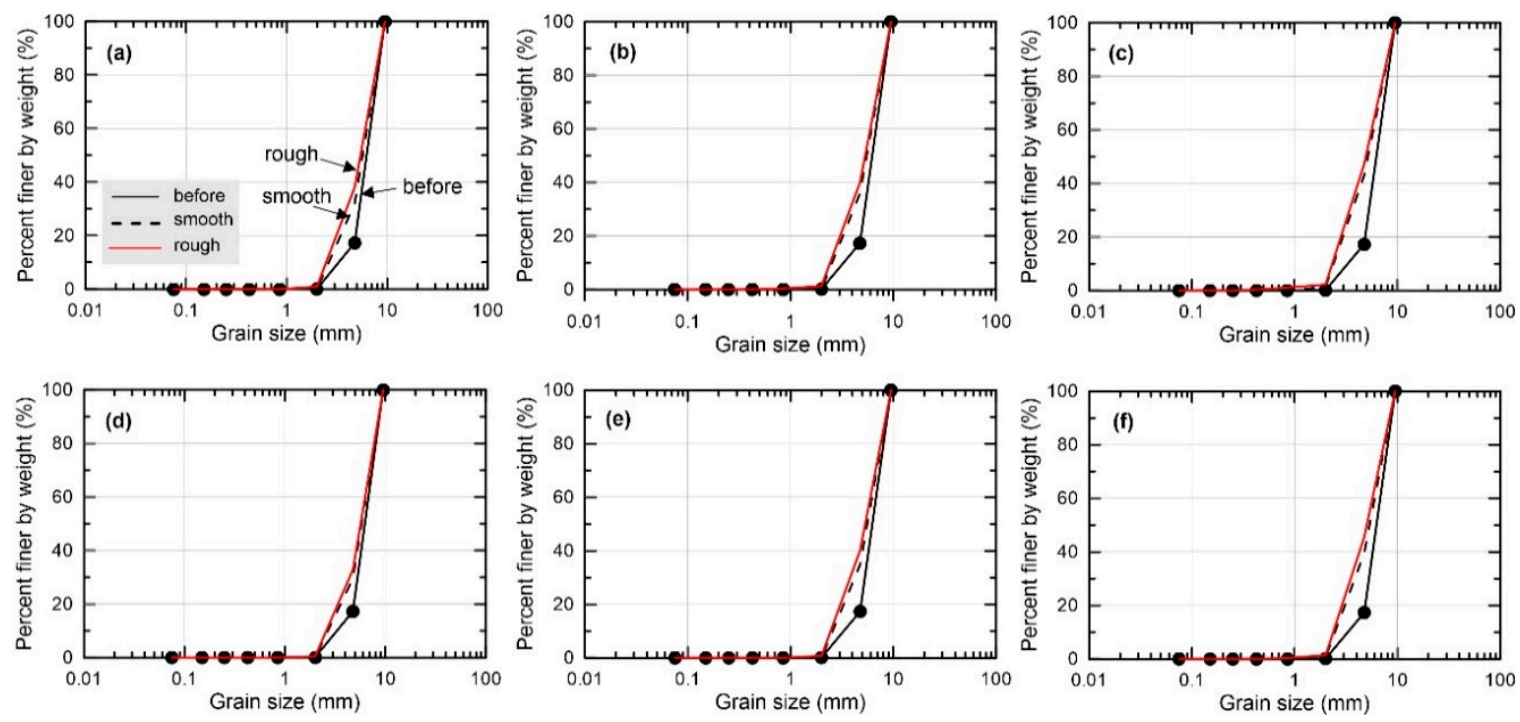

Figure 6. Grain crushing effect with respect to surface roughness: $(\mathbf{a}-\mathbf{c})$ Drained and $(\mathbf{d}-\mathbf{f})$ undrained conditions. $(\mathbf{a}, \mathbf{d}): 0.1 \mathrm{~mm} / \mathrm{s} ;(\mathbf{b}, \mathbf{e}): 0.5 \mathrm{~mm} / \mathrm{s} ;$ and $(\mathbf{c}, \mathbf{f}): 1 \mathrm{~mm} / \mathrm{s}$.

\section{Conclusions}

The effect of surface roughness on the shear strength of gravels using ring shear tests was examined. The shear characteristics measured from smooth and rough surfaces in a newly developed ring shear box were compared. The reduced wall friction using a smooth surface box may result in low shear strength estimates. Rough surfaces in test devices may result in overestimated shear strengths of geomaterials (clay to gravel-size), but they may also provide significant results if a slip occurs between two non-homogenous materials for the determination of the residual shear strength of gravelly soils. 
From the test results, the shear strength of granular materials depended on the drainage condition and shear velocity. The effect of surface roughness on shear strength, although small, could not be considered negligible with respect to minimization of the wall slip effect. The gravel exhibited a typical strain-hardening behavior regardless of the drainage and shear velocity when the gravel was firmly covered by the upper plate of the test device without applying normal stress $(0 \mathrm{kPa})$. The peak shear strength obtained from drained and undrained conditions increased with increasing shear velocity, when it may be assumed that the material exhibited plastic behavior; however, a large difference was caused by surface roughness when the shear velocity was increased. The grain crushing effect was not negligible and is actually dominant for both smooth and rough surfaces. A higher degree of grain crushing was observed for rough surfaces in the ring shear test. In a landslide transition, the reduction in shear strength with respect to the variation in pore water pressure and soft base (i.e., finer materials forming at the bottom of the slidebody) caused by shearing should be examined. In addition, the development of the shear zone, contraction, and dilatancy phenomenon, which depend on the normal stress and shear velocity, should be examined.

\section{Patents}

Korea Institute of Geoscience and Mineral Resources (KIGAM). Inventors: Jeong, S.W.; Song, Y.S.; Lee, C.O.; Kim, K.S. Ring shear apparatus considering wall-slip effect. US8656788B2. United States. 2014.

Author Contributions: Conceptualization, S.-W.J.; methodology, S.-W.J. and S.-S.P.; data and formal analysis, S.-W.J.; writing original draft, S.-W.J. and S.-S.P.; writing review and editing, S.-W.J and S.-S.P.

Funding: This research was supported by the KIGAM Research project (19-3413). This work was also supported by the National Research Foundation of Korea (NRF) grant funded by the Korea government (No. NRF-2018R1A5A1025137).

Acknowledgments: Special thanks to Hiroshi Fukuoka (1961-2018), who helped to install a large-sized ring shear apparatus at KIGAM. Special thanks to S.W. Kim who partially participated in the KIGAM project. The authors also extends a special thank you to the anonymous reviewers and editor for their valuable comments and recommendations for publishing this paper.

Conflicts of Interest: The authors declare no conflict of interest.

\section{References}

1. Zhan, W.; Fan, X.; Huang, R.; Pei, X.; Xu, Q.; Li, W. Empirical prediction for travel distance of channelized rock avalanches in the Wenchuan earthquake area. Nat. Hazards Earth Syst. Sci. 2017, 17, 822-844. [CrossRef]

2. Zhao, T.; Crosta, G.B. On the dynamic fragmentation and lubrication of coseismic landslides. J. Geophys. Res. Solid Earth 2018, 123, 9914-9932. [CrossRef]

3. Buttine, A.; Tatsuoka, F.; Kongkitkul, W.; Hirakawa, D. Viscous behavior of unbound granular materials in direct shear. Soils Found. 2008, 48, 297-318.

4. Tatsuoka, F.; Benedetto, H.D.; Kongkitkul, W.; Kongsukprasert, L.; Nishi, T.; Sano, Y. Modelling of ageing effects on the elasto-viscoplastic behavior of geomaterial. Soils Found. 2008, 48, 155-174. [CrossRef]

5. Shi, F.; Kojovic, T. Validation of a model for impact breakage incorporating particle size effect. Int. J. Miner. Process. 2007, 82, 156-163. [CrossRef]

6. Sebari, M.; Annan, C.D.; Konrad, J.M. On the mechanics and modeling of interfaces between granular soils and structural materials. Arch. Civ. Mech. Eng. 2018, 18, 1562-1579. [CrossRef]

7. Ebrahimian, B.; Noorzad, A.; Alsaleh, M. Modeling shear localization along granular soil-structure interfaces using elasto-plastic Cosserat continuum. Int. J. Solids Struct. 2012, 49, 257-278. [CrossRef]

8. Hu, L.; Pu, J. Testing and Modeling of soil-structure interface. J. Geotech. Geoenviron. Eng. 2004, 130, 851-860. [CrossRef]

9. Chen, X.; Zhang, J.; Xiao, Y.; Li, J. Effect of roughness on shear behavior of red clay-Concrete interface in large-scale direct shear tests. Can. Geotech. J. 2015, 52, 1122-1135. [CrossRef]

10. Zhang, G.; Zhang, J.M. Constitutive rules of cyclic behavior of interface between structure and gravelly soil. Mech. Mater. 2009, 41, 48-59. [CrossRef] 
11. Shahrour, I.; Rezaie, F. An elastoplastic constitutive relation for the soil-structure interface under cyclic loading. Comput. Geotech. 1997, 21, 21-39. [CrossRef]

12. Cavarretta, I.; Coop, M.; O'Sullivan, C. The influence of particle characteristics on the behaviours of coarse grained soils. Geotechnique 2010, 60, 413-423. [CrossRef]

13. Sandeep, C.S.; Senetakis, K. Effect of Young's modulus and surface roughness on the inter-particle friction of granular materials. Materials 2018, 11, 217. [CrossRef] [PubMed]

14. Uesugi, M.; Kishida, H. Frictional resistance at yield between dry sand and mild steel. Soils Found. 1986, 26, 139-149. [CrossRef]

15. Uesugi, M.; Kishida, H.; Uchikawa, Y. Friction between dry sand and concrete under monotonic and repeated loading. Soils Found. 1990, 30, 115-128. [CrossRef]

16. Yang, Z.X.; Jardine, R.J.; Zhu, B.T.; Foray, P.; Tsuha, H.C. Sand grain crushing and interface shearing during displacement pile installation in sand. Geotechnique 2010, 60, 469-482. [CrossRef]

17. Sadrekarimi, A.; Olson, S.M. Particle damage observed in ring shear tests on sands. Can. Geotech. J. 2010, 47, 497-515. [CrossRef]

18. Bagherimiyab, F.; Lemmin, U. Shear velocity estimates in rough-bed open-channel flow. Earth Surf. Process. Landf. 2013, 38, 1714-1724. [CrossRef]

19. Turcotte, D.L. Fractals and fragmentation. J. Geophys. Res. 1986, 91, 1921-1926. [CrossRef]

20. Zhang, M.; Yin, Y.; Hu, R.; Wu, S.; Zhang, Y. Ring shear test for transform mechanism of slide-debris flow. Eng. Geol. 2011, 118, 55-62. [CrossRef]

21. Tsoungui, O.; Vallet, D.; Charmet, J.C. Numerical model of crushing of grains inside two-dimensional granular materials. Power Technol. 1999, 105, 190-198. [CrossRef]

22. Hardin, B.O. Crushing of soil particles. J. Geotech. Eng. ASCE 1985, 111, 1177-1192. [CrossRef]

23. Einav, I. Breakage mechanics-Part I: Theory. J. Mech. Phys. Solids 2007, 55, 1274-1297. [CrossRef]

24. Langroudi, A.A.; Jefferson, I.; O'hara-Dhand, K.; Smalley, I. Micromechanics of quartz sand breakage in a fractal context. Geomorphology 2014, 211, 1-10. [CrossRef]

25. Sassa, K.; Wang, G.; Fukuoka, H. Performing Undrained shear tests on saturated sands in a new intelligent type of ring shear apparatus. Geotech. Test. J. 2003, 26, 257-265.

26. Sassa, K.; Fukuoka, H.; Wang, G.; Ishikawa, N. Undrained dynamic-loading ring-shear apparatus and its application to landslide dynamics. Landslides 2004, 1, 7-19. [CrossRef]

27. Wang, F.W.; Sassa, K.; Wang, G. Mechanism of a long-runout landslide triggered by the August 1998 heavy rainfall in Fukushima Prefecture, Japan. Eng. Geol. 2002, 63, 169-185. [CrossRef]

28. Hungr, O.; Morgenstern, N.R. High velocity ring shear tests on sand. Geotechnique 1984, 34, 415-421. [CrossRef]

29. Fukuoka, H.; Sassa, K.; Wang, G.; Sasaki, R. Observation of shear zone development in ring-shear apparatus with a transparent shear box. Landslides 2006, 3, 239-251. [CrossRef]

30. Torabi, A.; Braathen, A.; Cuisiat, F.; Fossen, H. Shear zones in porous sand: Insights from ring-shear experiments and naturally deformed sandstones. Tectonophysics 2007, 437, 37-50. [CrossRef]

31. Terzaghi, K.; Peck, R.B.; Mesri, G. Soil Mechanics in Engineering Practice, 3rd ed.; John Wiley and Sons Inc.: New York, NY, USA, 1996.

32. Jeong, S.W.; Park, S.S.; Fukuoka, H. Shear and viscous characteristics of gravels in ring shear tests. Geosci. J. 2018, 22, 11-17. [CrossRef]

33. Toyota, H.; Nakamura, K.; Sugimoto, M.; Sakai, N. Ring shear tests to evaluate strength parameters in various remoulded soils. Geotechnique 2009, 59, 649-659. [CrossRef]

34. Leroueil, S. Natural slopes and cuts: Movement and failure mechanisms. Geotechnique 2001, 51, 197-243. [CrossRef]

35. Wang, G.; Suemine, A.; Schulz, W.H. Shear-rate-dependent strength control on the dynamics of rainfall-triggered landslides, Tokushima Prefecture, Japan. Earth Surf. Process Landf. 2010, 35, 407-416. [CrossRef]

36. Shahnazari, H.; Rezvani, R. Effective parameters for the particle breakage of calcareous sands: An experimental study. Eng. Geol. 2013, 159, 98-105. [CrossRef]

37. Okada, Y.; Sassa, K.; Fukuoka, H. Excess pore pressure and grain crushing of sands by means of undrained and naturally drained ring-shear tests. Eng. Geol. 2004, 75, 325-343. [CrossRef]

(C) 2019 by the authors. Licensee MDPI, Basel, Switzerland. This article is an open access article distributed under the terms and conditions of the Creative Commons Attribution (CC BY) license (http://creativecommons.org/licenses/by/4.0/). 